www.jmscr.igmpublication.org

Impact Factor 5.84

Index Copernicus Value: 71.58

ISSN (e)-2347-176x ISSN (p) 2455-0450

crossref DOI: _https://dx.doi.org/10.18535/jmscr/v5i9.146

Journal Of Medical Science And Clinical Research

\title{
A Study on Carcinoma Penis
}

\author{
Authors \\ Dr M. Kumara Senthil ${ }^{1}$, Dr R.Yeganathan ${ }^{2}$, Dr N.Mohammed Niyamathullah ${ }^{3}$, \\ Dr A.Deepa ${ }^{4}$ \\ ${ }^{1}$ Assistant Professor of Surgery, Thanjavur Medical College \\ ${ }^{2}$ Associate Professor of Surgery, Trichy Govt Medical College \\ ${ }^{3,4}$ Resident, Department of General Surgery, Thanjavur Medical College
}

\section{Introduction}

Carcinoma penis is quite common in our country. Though in decreasing trends, its racial, cultural, socioeconomic factors plays role in its etiology. The aims of my study are

To find out the incidence of cancer penis amongst male in proportion to other malignancies which affect them, to find out the age group in which the patients are commonly affected. To find out the influence of the prognostic factors. On the long term survival, to analyze the treatment given and the recurrence rate and the time of recurrence after primary management of cancer is being made.

Materials and Method: This study included biopsy proven 30 cases of carcinoma penis.

Results: The commonest site of distribution in carcinoma penis is Glans. Ulcero proliferative lesion was the commonest presentation in carcinoma penis. The majority of cases were of Squamous cell carcinoma .The average interval between the onset of disease and the presentation is 8.2 months.

Conclusion: The custom of early Neonatal circumsion must be adopted as a prophylactic measure, particularly those with phimosis.

Keywords: Carcinoma penis, stages ,nodal status, follow-up.

\section{Introduction}

Carcinoma penis is a uncommon malignancy, accounting for upto $10 \%$ of all cancers in Asian population. Carcinoma Penis is almost unheard of races like the jews, who practice neonatal circumcision. A very low incidence is reported in Muslim population who practice circumcision at around school going age ${ }^{1}$. Squamous cell carcinoma accounts for at least $95 \%$ of all penile malignancies ${ }^{2}$. It most commonly occurs in sixth decade of life. There are a few predisposing conditions which are readily preventable. There are a few predisposing conditions which are readily preventable ${ }^{3}$. There exist a few premalignant lesions which predispose to carcinoma penis. It could be prevented or diagnosed early in most cases but for cultural and educational reasons it is often diagnosed later. The stage at presentation appears to be the most important prognostic indicator for survival.

\section{Materials and Methods}

During Dec 2015 to December 2016, for a period of over one year, 30 cases were admitted for treatment of Carcinoma Penis in the department of surgery at Thanjavur Medical College Hospital, Thanjavur. 
All the 30 cases were studied in detail with detailed clinical examination and special investigations like USG, MRI were done only wherever required.

Histopathological examination of the primary lesion was done by edge biopsy before proceeding to treatment. All the cases were subjected to surgery, chemotherapy and radiotherapy either singly or in combination depending upon the clinical stage ${ }^{4}$.

\section{Observation}

The incidence of cancer penis amongst male cancers were studied in this study.

There were around 2601 male cancer patient who reported to our hospital, during the period 2015 to December 2016. The incidence of cancer penis amongst the other cancers was derived accordingly. It is $1.15 \%$ when compared with total male cancers ${ }^{5}$. All the 30 patients who reported with the disease were included in finding out the age incidence.

\begin{tabular}{|l|c|c|}
\hline Age groups & No. of Patients & Percentage \\
\hline $31-40$ & 1 & $3 \%$ \\
\hline $41-50$ & 12 & $40 \%$ \\
\hline $51-60$ & 9 & $30 \%$ \\
\hline $61-70$ & 7 & $23 \%$ \\
\hline $71-80$ & 1 & $3 \%$ \\
\hline
\end{tabular}

The maximum incidence is found in the age group of 41-50 years. This conforms with the findings of Srivastava 1963 (Indian Journal of Surgery) ${ }^{6}$. The bulk of the age incidence in this study falls into the 40-70 years age group and it accounts to around $84.4 \%$ compared with the remaining groups ${ }^{7}$. The next criteria that was taken up in this study was circumcision and its incidence in prevention of cancer penis. There were no cases in the study who were circumcised at birth. 3 cases were circumcised in their later life.

\begin{tabular}{|l|c|c|}
\hline Circumcision & No. of patients & Percentage \\
\hline Done of birth & 0 & 0 \\
\hline Done at later age & 3 & $9 \%$ \\
\hline Not done & 27 & $91 \%$ \\
\hline
\end{tabular}

In this study were 28 Hindus and 2 Christians. There were no Muslims in this study. This again correlates with the findings of Srivastava, that Hindus are commonly affected ${ }^{15}$.

\begin{tabular}{|l|c|c|}
\hline Religion & No.of patients & Percentage \\
\hline Hindu & 28 & $94 \%$ \\
\hline Christian & 2 & $6 \%$ \\
\hline Muslims & 0 & 0 \\
\hline
\end{tabular}

All of them were squamous cell carcinoma (well, moderate \& poorly differentiated) Next, the growth pattern of the cancer was taken up for study. The growth pattern was analyzed either as papillary, an ulcero-proliferative variant or as a flat ulcerative variety. About 20 cases reported as a papillary variety and the rest 10 cases reported as a flat variety which means $60 \%$ of cases reported as a papillary one and the test $33 \%$ as flat one. Only $58 \%$ of patients with flat variety had regional lymph node metastasis whereas $68 \%$ out of the papillary pattern had regional lymph node metastasis.

\begin{tabular}{|l|c|c|}
\hline Growth pattern & No.of cases & Percentage \\
\hline Papillary & 20 & $66 \%$ \\
\hline Flat & 10 & $33 \%$ \\
\hline
\end{tabular}

The primary symptoms at presentation of all 30 cases were recorded. Patients who reported in this study presented with Growth penis, itching under foreskin, Phimosis, Inguinal mass with ulceration/fungation. The bulk of patients in this study presented primarily for a growth in penis. Patient presented with this complaint which amounted to $85 \%$ of cases.

\begin{tabular}{|l|c|c|}
\hline $\begin{array}{l}\text { Primary symptom at } \\
\text { presentation }\end{array}$ & No of cases & Percentage \\
\hline Growth penis & 26 & 86 \\
\hline Inguinal mass/fungation & 1 & 3 \\
\hline Itching under prepuce & 2 & 6 \\
\hline Phimosis & 1 & 3 \\
\hline
\end{tabular}

The bulk of cases, almost had their primary site of involvement in the glans penis. In 6 cases, prepuce was involved first. In another 3 cases, the primary involvement was both glans and prepuce at the same instance, Coronal sulcus and shaft were involved in two and one cases. 


\begin{tabular}{|l|c|c|}
\hline $\begin{array}{l}\text { Primary anatomical } \\
\text { site In penis }\end{array}$ & $\begin{array}{c}\text { No. of } \\
\text { cases }\end{array}$ & Percentage \\
\hline Glans & 17 & $57 \%$ \\
\hline Prepuce & 6 & $20 \%$ \\
\hline Glans \& prepuce & 3 & $10 \%$ \\
\hline Coronal sulcus & 2 & $8 \%$ \\
\hline Shaft & 1 & $4 \%$ \\
\hline
\end{tabular}

The average time of presentation is 8.2 is a bit on the higher side as compared to the literature -6 months. This may be due to the shyness, ignorance and lack of awareness. The nodal status of all 30 patients was taken into account in the next phase of the study. The nodal status was assessed clinically and classified into significant and insignificant nodal enlargement. Nodes which were greater than $2 \mathrm{~cm}$, involving vertical chain were taken as significantly enlarged.

Accordingly, in 12 patients there was no significant nodal enlargement, which accounts to $40 \%$ of cases. The remaining 18 cases, patients presented with significant nodal enlargement, which accounts to $60 \%$ cases. FNAC was done is significant nodal enlargement in 18 cases. Out of 18 patients, there was metastasis in FNAC in 8 cases. While the primary surgery was carried out in the remaining cases and were observed and followed up for inguinal metastasis.

Jackson's staging was taken up to find out the staging, at presentation. All 30 cases were taken up for study. 3 cases presented in Jackson's stage I. 7 cases presented in stage II, 12 cases in stage III and 8 cases presented in stage IV diseases. All patients were treated accordingly depending on the stage at which they presented. Almost $66 \%$ of cases presented in late stages, Jackson's stage III and IV.

\begin{tabular}{|l|c|c|}
\hline $\begin{array}{l}\text { Jackson's } \\
\text { stage }\end{array}$ & $\begin{array}{l}\text { No.of } \\
\text { cases }\end{array}$ & Percentage \\
\hline Stage I & 3 & 10 \\
\hline Stage II & 7 & 23 \\
\hline Stage III & 12 & 40 \\
\hline Stage IV & 8 & 26 \\
\hline
\end{tabular}

The treatment given to the patients includes a) treatment for the primary cancer, b) treatment for the metastatic nodes. The treatment for the primary cancer, depending on the extent of lesion in the penis, one of the following three surgeries was done. Partial amputation was done in 8 patients and total amputation with perineal urethrostomy with emasculation in 20 cases and without emasculation in 2 cases. In the 8 cases in which the nodes were positive for metastases anilloinguinal block dissection was carried out and the defect closed with sartorius muscle. In 3 cases prophylacticillio-inguinal dissection was done. For ulcerated, fungating, inoperable inguinal nodal secondaries, radiotherapy was given at a dose of 3000 to 5000 rads. For the treatment for primary tumor, In our unit we prefer emasculation along with total penectomy with perineal ureterostomy after considering the patients age and completion of family and with his full informed consent and counseling.

\begin{tabular}{|l|c|}
\hline Surgery & No. of cases \\
\hline Partial amputation & 8 \\
\hline $\begin{array}{l}\text { Total Amputation with } \\
\text { perineal urethrostomy } \\
\text { with emasculation }\end{array}$ & 20 \\
\hline Without emasculation & 2 \\
\hline
\end{tabular}

For the treatment for nodal metastases, Most of the patients in the patients after the primary treatment were not willing for repeat nodal surgery and were referred to radiotherapy and chemotherapy separately or in combination

\begin{tabular}{|l|c|}
\hline Treatment modality & No. of cases \\
\hline $\begin{array}{l}\text { Surgery (illoinguinal block } \\
\text { dissection) }\end{array}$ & 11 \\
\hline Radiotherapy & 4 \\
\hline
\end{tabular}

Regular follow up was obtained with only 10 patients which accounts to only $33 \%$ of patients. Of these 10 patients who were on follow-up. 4 patients landed up again with recurrence which amounts to $40 \%$. The peak of occurrence was noted at around the one year and the curve slopes down.

\begin{tabular}{|l|c|}
\hline $\begin{array}{l}\text { Time lapse since } \\
\text { primary surgery }\end{array}$ & No. of cases recurred \\
\hline$<6$ months & 0 \\
\hline$>6$ months & 1 \\
\hline 1 year & 3 \\
\hline
\end{tabular}




\section{Discussion}

It is already said in literature that, in the countries of Asia, Africa and South Africa penile carcinoma accounts for as many as $10 \%$ or $20 \%$ of male cancers $^{7}$. In this study, it just $1.15 \%$ which is definitely on the lower side. The bulk of the patients with the disease belonged to the 40-70 years age group and as in the literature: it is uncommon below 40 years of age. The mean age at diagnosis is around 53 years which is just years lower, as given in the literature . $^{8}$

The association between absence of circumcision and the disease is already well established. And also from this study, it has been clearly seen that circumcision done at a later stage in life does not fully prevent the occurrence of the disease. The growth patterns of the cancer have specific significance. The type of the growth pattern has been correlated with the frequency of regional lymph node metastasis. Usually patients with a flat growth pattern have a greater incidence of inguinal lymph involvement ${ }^{11}$. In this study, to our surprise it was the papillary variety that had more regional lymph node involvement that the pattern. The primary symptom at presentation in most of the patients in this study was a growth in their penis. The shyness on this part of the patient brings them at a later date with a full blown growth in the penis with or without regional lymph nodes.

The primary site of location of cancer penis is in the glans in this study, which very well correlates with that in literature ${ }^{12}$. Second most common site is prepuce.

The nodal status of the patients were taken into account and it was found that only $66 \%$ of patients presented with palpable inguinal lymphadenopathy which very well falls into the range of $20 \%$ $90 \%$ as in literature. The patients with metastasis in nodes in this study amounted to $30 \%$. The reason behind such gross increase in nodal metastasis is the negligence on the part of the patient to present early to surgeon, which makes things still difficult and survival rate worse.
The prognosis in cancer penis appears to correlate only with stage at presentation. $67 \%$ of cases which presented in late stages of Jackson's classifycation in this study fall into the bad prognosis group $^{13}$.

Early presentation to the surgeon saves time for the him and improves the prognosis for the patient. The primary cancer was managed depending on the extent of the lesion either by partial amputation or total amputation with perineal ureterostomy. An ilio-inguinal block dissection was carried out in FNAC positive cases. If the general condition of the patient is satisfactory then radiation is given at full dose of 5000 rads - 200 rads for 5 days a week for 5 weeks.

If the general condition is poor $300 \mathrm{rads} / \mathrm{day}$ for 10 days in 2 weeks In advanced cases chemotherapy was tried though its role is very limited. Cisplatin, Bleomycin, 5-Flurocuracil and Methotrexate combination drugs were given ${ }^{14}$.

From this study, it is clear that, not many patients turn up for follow up. Hence, the occurrence of nodal disease in their late stages becomes much more common.

Again, the peak at which the recurrence of malignancy occurs is around the one year which clearly indicates that follow up till the first year has to be intensified in our patients.

\section{Conclusion}

The Age incidence of Carcinoma penis is high in fifth decade. The commonest site of distribution in carcinoma penis is Glans. Ulceroproliferative lesion was the commonest presentation in carcinoma penis. The majority of cases were of Squamous cell carcinoma. The average interval between the onset of disease and the presentation is 8.2 months Maximum number of cases presented to the hospital in Stage III disease. The prognosis depends upon the stage and nodal status at presentation. Partial amputation was done for Stage 1: Total Amputation for Stage II: surgery alone or surgery and radiotherapy for Stage III. 
Radiotherapy and chemotherapy in combination with surgery or alone for stage IV disease.

Carcinoma penis cases should be followed up at least for one year, as the recurrence is higher at around one year mark.

\section{References}

1. Bailey and love $25^{\text {th }}$ edition.

2. Short case of Das.

3. Camphbel's urology new edition.

4. Oxford Textbook of Oncology $\left(2^{\text {nd }}\right.$ edition). EdsSouhami et al. Oxford University Press, 2002.

5. Jackson SM: The treatment of carcinoma of the penis, Br J urol 1966; 53: 33-35.

6. Article of Shrivatasava, Indian Journal of surgery.

7. Persky L. Dekernion J: Carcionoma of the penis. CA 1986; 36:258-273.

8. Fraley EE, Zhang G, Manuvel C, Niehans GA: The role of ilio-inguinal lymphadenectomy and significance of histological differentiation in treatment of carcinoma of he penis. J Urol 1989; 142:1478-1482.

9. MeDougal WS: Carcionma of the penis: Improved survival by early regional lymphadenectomy based on the histological grade and depth of invasion of the primary lesion. J Urol 1995; 154: 1364-1366.

10. Jackson SM: The treatment of carcionoma of the penis Br J Urol 1966; 53: 33-35.

11. Solsona E, Jborra J, Ricos JV, et al : Corpus cavernosum invasion and tumor grade in the prediction of lymph node metastases. EurUrol 1992; 22: 115-118.

12. Johnson De, Lo RK: Management of regional lymph nodes in penile carcionoma; Five year results following therapeutic groin dissections. Urology 1984; 24; 352-355.

13. Srinivas V, Morse MJ, Herr HW, et all: Penile cancer: relation of extent of nodal metastases to survival. J Urol 1987; 137: 880-886.

14. Catalona WJ: Role of Iymphadenectomy in carcinoma of the penis urolClin NA 980; 7 85-89

15. Ravi R: Morbidity following groin dissection for penile carcinoma. Br J Urol 1993; 941-45. 